\title{
The Time Machine: challenging perceptions of time and place to enhance climate change engagement through museums
}

\author{
Henry McGhie*, Sarah Mander**, Asher Minns***
}

\begin{abstract}
This article proposes that applying time-related concepts in museum exhibitions and events can contribute constructively to people's engagement with climate change. Climate change now and future presents particular challenges as it is perceived to be psychologically distant. The link between this distance and effective climate action is complex and presents an opportunity for museums, as sites where psychological distance can be explored in safe, consequence-free ways. This paper explores how museums can help people develop an understanding of their place within the rhetoric of climate change, and assist them with their personal or collective response to the climate challenge. To do so, we find that two time- and place-related concepts, Brian Eno's the Big Here and Long Now and Foucault's heterotopia, can provide useful framings through which museums can support constructive climate change engagement.
\end{abstract}

Key words: Museums, climate change, futures, engagement, psychological distance

\section{Introduction}

Climate change presents one of the most serious challenges to human society and the environment, where both reducing emissions and adapting to the impacts of climate change involve major systemic change to society and the economy. Given the scale, nature and speed of these systemic changes, greater public engagement has been considered to be essential for numerous reasons, including the building of democratic support for action (see for example Carvalho and Peterson 2012), and to improve policy making (Pidgeon and Fischhoff 2011), notably through the incorporation of diverse perspectives (Chilvers et al. 2018). From an international climate change policy perspective, the United Nations Framework Convention on Climate Change (UNFCCC) (1992) and Paris Agreement (2015) each include an article on education, training, public awareness, public participation and access to information (article 6, which also includes 'international co-operation', and article 12 respectively, referred to jointly as Action for Climate Empowerment). ${ }^{1}$ The UN Sustainable Development Goals, a blueprint for international sustainable development from 2015-30, include a goal (13) to 'Take urgent action to combat climate change and its impacts'; this goal includes a target to 'Improve education, awareness-raising and human and institutional capacity on climate change mitigation, adaptation, impact reduction and early warning'. ${ }^{2}$

Climate change engagement may be defined as 'an ongoing personal state of connection' with the issue of climate change (Lorenzoni et al. 2007: 446; Whitmarsh et al. 2011). As connection incorporates a broad range of aspects that constitute what we think, feel and do about climate change - cognitive, socio-emotional and behavioral aspects - simply knowing more about climate change does not necessarily promote action and, where information provision does not provide people with an understanding of the actions that are needed or is demotivating, it can inadvertently disempower people (Moser and Dilling 2004; O'Neill and Nicholson-Cole 2009). The three elements of climate change engagement - cognitive, socio-emotional and behavioural - approximate to the three domains of the learning model used by UNESCO as a framework for Global Citizenship Education (GCED) and Education for Sustainable Development (ESD); GCED aims to educate people 'to know, to do, to be, 
and to live together', empowering learners of all ages to play an active role in overcoming global challenges (UNESCO 2015: 22; see also UNESCO 2017).

Cognitive, socio-emotional and behavioural aspects connect in non-linear, nonsequential ways, but are iterative and dialogical. Engaging constructively with all three aspects presents a plausible route towards constructive engagement with the topic, allowing people to make sense of climate change in their daily lives, connecting thoughts and concerns with choices and actions (Lorenzoni et al. 2007).

Museums have the potential to be important venues to promote public education, empowerment and action around climate change (see below), and were formally recognized at COP24 in Katowice (Poland) in December 2018 as key sites for supporting Action for Climate Empowerment. ${ }^{3}$ In this paper, we explore two questions: 1) how can museums help people develop their understanding of what climate change means to them? and 2) how can museums help facilitate a response to the climate challenge? These questions are explored using two concepts, Michel Foucault's work on heterotopias and Brian Eno's the Big Here and Long Now. We suggest that these can be used to challenge conventional ways of thinking about time and place, and frame climate change engagement in museums in a way that allows people to negotiate and navigate the psychological distance of climate change in constructive ways. In Section 2 we provide an overview of the potential roles of museums in responding to climate change; in Section 3 we discuss the literature on psychological distance. In Sections 4 and 5 we present Michel Foucault's work on heterotopias, and Brian Eno's the Big Here and Long Now, in relation to climate change focused exhibitions in museums.

\section{Museums and climate change}

Fiona Cameron and her colleagues have written extensively on the role[s] of museums in the context of climate change. They explored the current and potential roles of museums (specifically, natural history museums, science museums and science centres) in society in relation to climate change, in Australia and the US as part of the 'Hot Science Global Citizens: The Agency of the Museum Sector in Climate Change Interventions' project (2008-12). Their results demonstrated significant differences between the current and desired roles of museums in respect of climate change among the public and museum workers. The project suggested nine strategic positions for museums to adopt to better meet the desires of their publics, as well as key role changes for science centres and museums (based on large differences between public and museums' desires for particular positions) (Cameron 2011, 2012). Results of the 'Hot Science' project were used to develop a set of nine principles intended to support museums and science centres to act meaningfully on climate change (Cameron et al. 2013).

Cameron (2010) introduced the concepts of 'liquid museums' and 'liquid governmentalities' to explore how museums can support action and empowerment around contemporary issues such as climate change, without exercising authoritarian control (see also Cameron 2007, 2011). Cameron et al. (2013: 9) wrote

The big task of the museum sector is not only to inform publics on the science of climate change but also to equip citizens with tactical knowledges that enable participation in actions and debates on climate change that affect their futures.

They also suggested that

museums and science centers can engage a future-oriented, forward thinking frame, as places to link the past to the far future through projections of what might happen as places to offer practical governance options and as places to present long-term temporal trajectories. They offer an antidote to short-term thinking and the failure of governments to act, by presenting the variable dispositions, ideologies, and governance options, thereby constructing a mediated view of the future as a series of creative pathways (Cameron et al. 2013: 11; see also Cameron and Neilson 2015).

Notwithstanding the wide potential of museums to contribute meaningfully to addressing the challenges of climate change, Canadian Robert Janes has noted that, for the most part, museums have been slow to incorporate climate change into their work, risking their own long-term relevance (Janes 2009, 2016). 
In Curating the Future, Newell et al. proposed that museums can be effective places for supporting discussion and action to address climate change. Through a wide range of case studies that read or re-read objects and exhibitions in the context of rapid climate change, they explored how contemporary museums have been adjusting their conceptual, material and organizational structures to reposition themselves on four deeply rooted trajectories that separate colonized and colonizer, Nature and Culture, local and global, authority and uncertainty (Newell et al. 2017).

Rather than direct their attention to protecting material from the past, museums can direct their work (the full range of their work, including collecting and public-facing work) towards supporting and enabling better futures more actively. Natural history museums and science centres could readily engage around contemporary issues such as climate change and other environmental topics (as could many other kinds of museums) to become 'natural futures museums'; military museums could focus on topics around the causes and consequences of contemporary wars in order to reduce future conflicts; and ethnographic museums could emphasize issues around cultural diversity and identity in the face of globalization and social inequality (see e.g. Basu and Modest 2015; Dorfman 2018). This approach recognizes the interconnectedness of different forms of heritage - material, natural, cultural and intangible - and connects with emerging ideas of heritage as a future-making practice, e.g.

heritage is not a passive process of simply preserving things from the past that we choose to hold up as a mirror to the present, associated with a particular set of values that we wish to take with us into the future. Thinking of heritage as a creative engagement with the past in the present focuses our attention on our ability to take an active and informed role in the production of our own 'tomorrow' (Harrison 2013: 4).

In previous work, we have proposed sets of recommendations for museums, to support them to develop constructive climate change engagement activities (McGhie et al. 2018; McGhie 2019). The present paper builds on these contributions, by providing a more theoretical framework drawing on applied social psychology perspectives.

\section{Psychological distance, climate change and museums}

From the perspective of many in the Global North, climate change is widely perceived to be a distant phenomenon, something which will happen in the future, in far-away places (so impacting most on those in the Global South), and which has great uncertainty associated with it in terms of the likelihood, scale and nature of impacts. The proximity of climate change can be usefully described in terms of 'psychological distance', a theoretical construct defined as 'a subjective perception of distance between the self and some object, event, or person' (Wang et al. 2019). Four dimensions of psychological distance have been identified: temporal distance (time), spatial distance (place), social distance (cultural difference), and hypothetical distance (certainty or uncertainty) (Trope and Liberman 2010). These, together, describe the 'perception of when [an event] occurs, where it occurs, to whom it occurs and whether it occurs' (Trope and Liberman 2010: 442, quoted in Wang et al. 2019: 2).

As the need to mitigate climate change becomes more urgent (Committee on Climate Change 2019a, 2019b) and climate impacts are felt more strongly (see for example Burke and Stott, 2017; Van Oldenborgh et al. 2017), the influence of the proximity of climate change on people's decisions to reduce their greenhouse gas emissions or adapt to climate impacts has been suggested as 'a promising strategy for increasing public engagement with climate change' (Jones et al. 2017). Reducing psychological distance has frequently been suggested as a means of increasing public engagement with, and action to address, climate change (see Schuldt et al. 2018 for references). There is indeed evidence from several studies that public concern about climate change decreases as the psychological distance of climate change increases, but this is not a simple or straightforward panacea (see Wang et al. 2019 for references). Exploring whether pro-environmental behaviour was best predicted by concrete, close perceptions of climate change (psychological closeness), or abstract, distant perceptions (large psychological distance), Spence et al. (2012) found that, among a 
nationally representative cohort of people in Britain aged over fifteen years of age $(N=1,822)$, psychological closeness with energy futures and climate change was associated with higher levels of concern and preparedness to reduce energy consumption; so, people who have direct experience of climate impacts, which brings it close in terms of time, place and certainty, have been reported as being more willing to take mitigation actions (Spence et al. 2012; Broomell et al. 2015). However, Spence et al. (2012) also found that greater distance on the social distance dimension was associated with higher preparedness to take personal action, with people expressing concern for people in the Global South who were likely to be personally more seriously impacted by climate change than the survey respondents considered they would be themselves.

Scholars have considered climate change and psychological distance in relation to Construal Level Theory (Brügger et al. 2016; Griffioen et al. 2016; Wang et al. 2019), which is concerned with the ways in which our mental representations depend on their closeness to our present situation. Phenomena of which we have direct experience, or which are close to our present situation, require little mental effort to interpret or construe (low-level construal). By contrast, phenomena which are spatially, temporally or socially distant, or where there is inherent uncertainty, require a greater amount of effort to be represented mentally, and will result in high-level construals which will be more abstract and less concrete (Brügger et al. 2016). According to this rationale, if climate change is perceived as distant, it may be conceived in an abstract way. Abstractness has been found to encourage a goal-centred mind-set, allowing for the exploration of more distant, creative solutions (Liberman and Trope 2008), and enhancing self-control (Trope and Liberman 2010, see Wang et al. 2019). However, a concrete construal of climate change may promote psychological closeness, which may foster concern (Trope and Liberman 2010; Van Boven et al. 2010). Wang et al. (2019) found that psychological closeness to climate change predicted pro-environmental behaviour, while construal level produced inconsistent results; manipulations of both features did not increase pro-environmental behaviour. They also found that the presumed close association between psychological distance and construal level may not hold true in the case of climate change.

In one study on construal level and environmental issues, interventions were most effective when participants were asked to find an abstract goal in a specific context, or a specific goal in an abstract context, in that they facilitated both a greater awareness and a consideration of how to take personal action (Rabinovich et al. 2009; see also Ejelöv et al. 2018). Moreover, McDonald et al. (2015) found a complex relationship, where direct experience (short psychological distance) did not necessarily lead to action, and that 'the optimal framing of psychological distance depends on 1) the values, beliefs and norms of the audience, and 2) the need to avoid provoking fear and resulting avoidant emotional reactions'. To Wang et al., this 'suggests that both psychological closeness and distance can promote pro-environmental action in different contexts' (Wang et al. 2019: 3).

Overall, research in this area demonstrates that the relationship between psychological distance and climate change is complex, but many scholars have pointed out that inspiring more, or sufficient, action on climate change is not simply a matter of bringing climate change closer (see for example Brügger et al. 2015; McDonald et al. 2015; Brügger et al. 2016; Schuldt et al. 2018; Wang et al. 2019).

\section{A role for museums}

Clearly, climate change presents an especially complex topic when considering psychological distance and construal level. However, acknowledging this complexity and considering the dimensions of psychological distance and construal level within the design of, and intended outcomes from, climate change engagement activities has the potential to increase their effectiveness. This may help promote people's constructive engagement with climate change as a result, and offers a distinctive role for museums to play.

Climate change engagement activities may provide opportunities to explore climate change considering the social, spatial (see for example Lorenzoni et al. 2007; Spence et al. 2012) and temporal dimensions of psychological distance and climate change (see for example Rabinovich et al. 2010). These we consider to be of particular relevance in a museum setting as museums use their artefacts, collections and exhibits to connect ('engage') visitors 
with other places and times. They use their collections to tell and create stories in formal, informal and non-formal educational activities that can resonate with, or challenge, the values and world views of their visitors (McGhie et al. 2018; McGhie 2019). Science museums and science centres can also play a particular role in supporting people to understand the key importance of uncertainty and probability in science, which relates to the hypothetical dimension of psychological distance and climate change. Increasing numbers of museums are also seeing themselves as place-makers or spaces for activism, and are actively trying to engage people with thinking about the future (e.g. Janes 2016; Janes and Sandell 2019).

We now move on to present the Big Here and Long Now and heterotopia, two concepts that provide alternative ways of thinking about time and place. We consider how these can usefully be 'deployed' to frame museum engagement on climate change and provide examples of where museums are using them.

\section{The Big Here and Long Now}

Observing the fast pace of New York lifestyles, musician Brian Eno observed 'everyone seemed to be passing through. It was undeniably lively, but the downside was that it seemed selfish, irresponsible and randomly dangerous'. Eno conceived of this as a 'short now', with a fast pace of life, and short timeframes for decisions and for considering the impacts of those decisions. However, this also suggested to Eno the possibility of the opposite, the 'long now'. Eno also considered how people think about 'here': for some it is their immediate surroundings, a 'small here', while for others the spatial scale is wider, encompassing neighbourhoods, towns and indeed the world, a 'big here'. Eno conceived of a 'Big Here' and 'Long Now', combining these considerations of place and time respectively. ${ }^{4}$

The idea of the Long Now became a manifesto for the Foundation of the Long Now, established in 1996 to encourage a long-term view and stewardship of the long-term (Brand 1999). The first project of the Foundation was the idea of a 10,000-year clock, which is currently being built in Texas (see Brand 1999 for background). Futurist Danny Hillis, who devised the concept of the clock, wrote:

I cannot imagine the future, but I care about it. I know I am a part of a story that starts long before I can remember and continues long beyond when anyone will remember me. I sense that I am alive at a time of important change, and I feel a responsibility to make sure that the change comes out well. I plant my acorns knowing that I will never live to harvest the oaks. I have hope for the future. ${ }^{5}$

Kevin Kelly, also of the Long Now Foundation, popularized a quiz developed by naturalist Peter Warshall, which aimed to encourage people to think in a larger geographical context, namely a river's watershed. ${ }^{6}$ Kelly broadened the concept to encourage people to think on a macro scale, to constitute a Big Here, which could extend to a country, the planet or indeed beyond the planetary scale. The combination of the Big Here and Long Now has been adopted by the Long Now Foundation as a means for broadening both a sense of place and time, that 'now' is not a particular moment but a moment that connects with what has gone before and what will follow, and 'here' is bigger than the small piece of ground that we stand upon. 'Now' and 'here' become entirely subjective in terms of their scope.

Conceptualizing and framing climate change in terms of the Big Here and Long Now, in contrast to the Small Here and Short Now, opens a space for stretching our thinking about place from beyond our immediate surroundings and towards a broader conceptualization of society, both spatially and temporally. This draws our attention to processes, contexts and consequences of decisions - our individual and collective decisions - over a broad range of scales and timeframes. Such an approach may help promote climate change engagement in people's everyday lives, and climate action through responsible, sustainable consumption.

\section{Heterotopia}

The Paris Agreement and the Sustainable Development Goals represent an idealized, desired future state. This is a utopia, in the properly ambiguous sense of the word: both an 'ideal place' (a 'eutopia') and, being in the future, a 'nowhere place' (an 'outopia') (see, 
especially, Marin 1984, 1992; Hetherington 1997). In exploring and envisioning this 'other place', we can draw on one of the most familiar time-related concepts relating to museums, Michel Foucault's concept of museums as heterotopia. Foucault introduced the concept in 1967, during a period of work that was concerned with archaeology and archives (Foucault 1986, 1998; see Hetherington 2015). Foucault noted 'we are in the epoch of simultaneity: we are in the epoch of juxtaposition, the epoch of the near and far, of the side-by-side, of the dispersed' (Foucault 1986: 22). Foucault distinguished sites that have the 'curious property', that 'suspect, neutralize, or invent the set of relations that they happen to designate, mirror, or reflect' (Foucault 1986: 24). He identified two such sites; firstly, utopias, sites with no real place that represent society in a perfected form. Secondly, there were sites,

something like counter-sites, a kind of effectively enacted utopia in which the real sites, all the other real sites that can be found within the culture, are simultaneously represented, contested, and inverted. Places of this kind are outside of all places, even though it may be possible to indicate their location in reality (Foucault 1986: 24).

These are, of course, Foucault's heterotopia. Hetherington has built on this definition, to construe heterotopia as 'spaces of alternate ordering. Heterotopia organize a bit of the social world in a way different to that which surrounds them' (Hetherington 1997: viii). Foucault held there to be six principles of heterotopia: firstly, that they probably exist in every culture. Second, and importantly for our purposes, that heterotopia can be made to function in a very different fashion at different times. Third, the heterotopia is capable of juxtaposing several sites and spaces that are themselves incompatible. Fourth, heterotopia are most often linked to slices in time, and 'the heterotopia begins to function at full capacity when men arrive at a sort of absolute break with their traditional time' (Foucault 1986: 26). Most notably, in this respect, Foucault wrote:

...there are heterotopias of indefinitely accumulating time, for example museums and libraries. Museums and libraries have become heterotopias in which time never stops building up and topping its own summit, whereas in the seventeenth century, even at the end of the century, museums and libraries were the expression of an individual choice. By contrast, the idea of accumulating everything, of establishing a sort of general archive, the will to enclose in one place all times, all epochs, all forms, all tastes, the idea of constituting a place of all times that is itself outside of time and inaccessible to its ravages, the project of organizing in this way a sort of perpetual and indefinite accumulation of time in an immobile place, this whole idea belongs to our modernity. The museum and the library are heterotopias that are proper to western culture of the nineteenth century (Foucault 1986: 26).

Fifth, heterotopia are not freely accessible: there are limitations or rules around their openness. Finally, heterotopia have a function in relation to all remaining space, either 'to create a space of illusion that exposes every real space'; 'their role is to create a space that is other, another real space, as perfect, as meticulous, as well arranged as ours is messy, ill constructed, and jumbled' (Foucault 1986: 27). Hetherington notes that heterotopia are ambiguously articulated, whether as 'other places / places of otherness / emplacements of the other' (Hetherington 2015: 35).

While Foucault's work on heterotopia has, understandably, been related to museums (see Lord 2006 for examples), as Lord points out, Foucault's primary discussion of museums as heterotopia was in terms of the building of an archive: of the materiality of the museum that builds up and the knowledges associated with that material, rather than the constant creation and recreation of the past from an interrogation of that material (they 'endlessly accumulate times in one space through the material objects they contain and the knowledge associated with them' (Hetherington 2015: 35)). Lord expanded on Foucault's work on heterotopia to emphasise the key importance of narrative and interpretation in museums' function as heterotopia: 
The museum is the space in which the difference inherent in its content is experienced. It is the difference between things and words, or between objects and conceptual structures: what Foucault calls the 'space of representation' (1970: 130)... the space of representation is the heterotopia (Lord 2006: 4-5).

It is worth noting that museums' attempts to represent everything or to 'constitute a place of all times that is itself outside time', to draw on Foucault's phrase (Foucault 1986: 26, see Hooper-Greenhill 2000; Lord 2006), are increasingly unsustainable or impossible. Their attempts to exist 'outside of time and inaccessible to its ravages' (Foucault 1986: 26) are similarly tested by social, economic and environmental challenges, including climate change. Heterotopia can be repurposed to explore the time that does not yet exist, the future, exploring Foucault's brief mention on utopias as sites that 'have a general relation of direct or inverted analogy with the real space of Society. They represent society itself in a perfected form, or else society turned upside down, but in any case these utopias are fundamentally unreal spaces' (Foucault 1986: 24). ${ }^{7}$ Lord notes how 'the definition of museum as heterotopia explains how the museum can be progressive without subscribing to politically problematic notions of universality or 'total history', but as a 'growth of capabilities". She concludes that 'museums are best placed to critique, contest and transgress those problematic notions, precisely on the basis of their Enlightenment lineage' (Lord 2006: 12). Here, then, we can see potential for museums as sites for subverting and imagining other potential societies and futures, and a 'growth of capabilities' speaks well to the language of a productive future where, in the language of the Sustainable Development Goals 'no-one is left behind'.

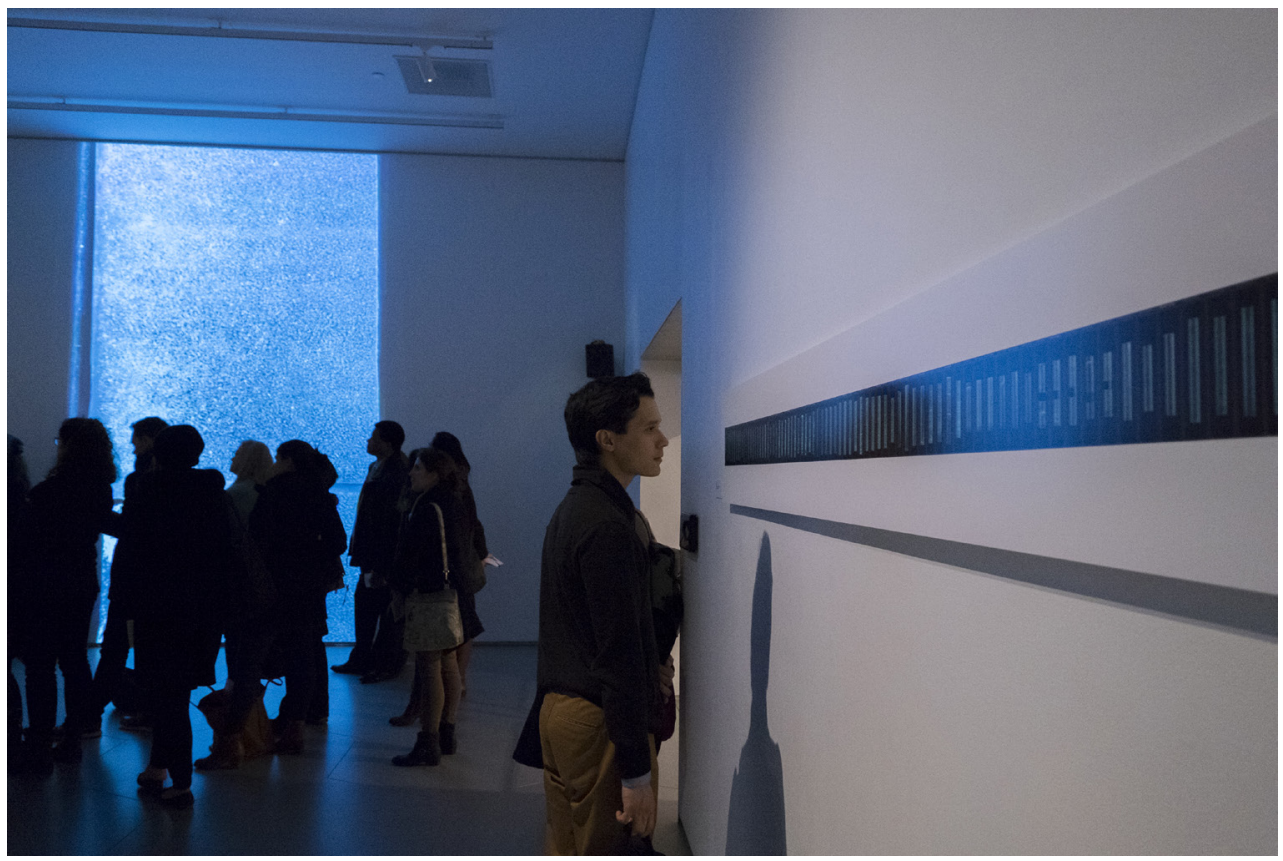

Figure 1. In Human Time exhibition, Climate Museum, New York, showing Peggy Weil's film 88 Cores, image credit: Sari Goodfriend, courtesy of the Climate Museum.

\section{Applying the Big Here and Long Now, and heterotopia in museums}

In this section we consider how the two aforementioned concepts can be related to exhibitions and events linked to climate change, and how they can be factored into new developments. Museums typically have collections shown in exhibits that originate from different time periods and places, which speak to both the Big Here and the Long Now, extending the viewer's or 
participant's 'here' or 'now'. Considering the Big Here and Long Now can provide a useful context for exploring issues such as climate change, sustainability and citizenship, and can be seen in many exhibitions about climate change. The Big Here and Long Now becomes a useful lens which, together with considerations of psychological distance and construal level, allows us to consider how museum interventions are aligning, or not, with these concepts.

To take one example, the recent exhibition Human Nature (2019-20) at the World Cultures Museum in Stockholm conveys the key message 'it's all connected. How we live our lives is closely related to the state of our earth'. ${ }^{8}$ This exhibition and this strapline extend our sense of the here and now; they seem to attempt to reduce psychological distance, linking our lives with their impacts; by giving form and voice to these relationships the museum appears to make our construal of the relationship more concrete. The Climate Museum in New York staged a two-part exhibition, In Human Time (2017-18) by Peggy Weil and Zaria Forman, to explore 'intersections of polar ice, humanity, and time' (fig. 1). ${ }^{9}$ A film, by Peggy Weil, shows close-ups of ice cores that were drilled down two miles into the Greenland Ice Sheet, spanning 110,000 years; the film pans very slowly over the ice core, revealing the subtle changes in colour, bubbles and texture of the ice. Weil wrote 'The pace and scale of the work is a gesture towards deep time and the gravity of climate change'..$^{10}$ Zaria Forman's work consisted of a reproduction of a hyper-realistic image of an Antarctic iceberg, grounded in an 'iceberg graveyard' in Antarctica. The image was accompanied by a timelapse video, illustrating the process of the creation of the image. This single exhibition, in two parts, demonstrates a complex interplay of the concepts of the Big Here and Long Now, with the long timescale of the development of the ice in the ice core reflected in the slow pace of the film. The grounded, melting iceberg in the Antarctic reflects a concrete construal of the effects of climate change, while the far away nature of the Antarctic speaks of a large psychological distance.

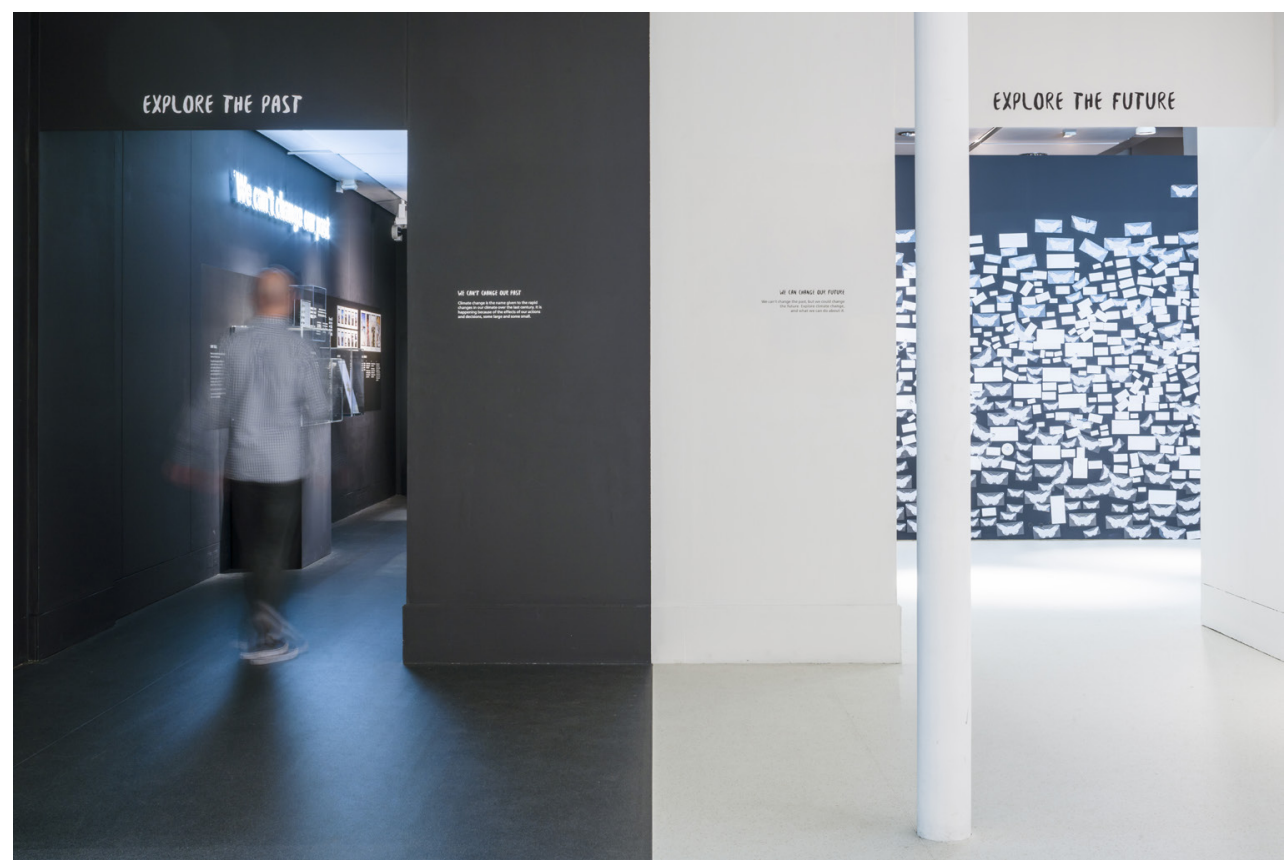

Figure 2. Climate Control exhibition, Manchester Museum, UK, 2016, showing two entrances where visitors decided whether to explore the past or the future. Image credit: Gareth Gardner.

To take another example, the exhibition Climate Contro/ was shown at Manchester Museum (University of Manchester) during the city's time as European City of Science in 2015-16. Two of the authors (HM and SM) were involved in the development of the exhibition and accompanying programme. The exhibition was accompanied by a range of activities, developed 
in partnership with and involving academics from the University of Manchester and a range of NGOs and community organizations, as well as Manchester Climate Change Agency, which is responsible for developing and overseeing the city's climate change mitigation and adaptation strategy. Through these partnerships, the exhibition was used as the inspiration for, and reinterpreted through, a range of engagement activities to promote climate change awareness, adaptation and mitigation.

The exhibition had two entrances where visitors could choose either to explore climate change in the past (and present) or the future (fig. 2). The section of the exhibit on the past (and present) included exhibits on fossil fuels and fossils from millions of years ago, a range of Arcic wildlife impacted by climate change today, and photographs of people impacted by climate change around the world. The exhibit emphasized the connection between events over very long timescales: the trapping of sunlight by plants millions of years ago, their preservation as fossils, and the burning of fossil fuels over the last three centuries. It also emphasized the connection between far-distant places: the burning of fossil fuels in industrial countries, and climate impacts in the Arctic and around the world. The connection was illustrated by birds that spend the summer in the Arctic and migrate to the UK in the winter, to foster a sense of shared wildlife. Images of people affected by flooding in Bangladesh, sea-level rise in Belize, and people who rely on meltwater from vanishing glaciers in Ladakh and Peru, showed the real-life impacts of climate change on people round the world. The exhibit explored climate change from a local, place-specific context, in terms of the industrial history of Manchester, a global dimension linking Manchester to the Arctic, and to a range of different communities around the world. A taxidermy mount of a Polar Bear was accompanied by the open-ended question 'are we so different?'. This exhibition thus approached climate change from an abstract and concrete construal level, brought in various psychological distances, and was strongly linked with the Big Here and Long Now concept. The viewer or participant was always intended to be psychologically close to the place - the museum and exhibition gallery - where the exhibition was shown.

Seeking to empower visitors to the Climate Control exhibition to consider their place in this and the myriad of possible alternative future worlds, the other half of the exhibition was entitled 'explore the future'. This part of the exhibition did not contain museum objects, but instead was a space with information on climate change action at local, national and international scales and activities which invited people to share ideas on "changing the future' and to reflect on the ideas of others. The exhibition was intended to look unfinished when it first opened, as the future is not set in stone. This part of the exhibition was, we feel, a heterotopia in the sense that it asked people to create a place that is not a real place, but which has a role in relation to the external world.

The two halves of the exhibition were divided by a central wall. Visitors to the 'explore the past' section were invited to stick a small black sticker to a white wall to represent their carbon footprint, and to emphasize that together we make a large collective impact. This can be regarded as a concrete construal level. On the reverse side of the wall, in the 'explore the future' section, visitors were invited to add stickers on which they wrote their ideas on how to create a sustainable future. This, being abstract, we feel represented a higher construal level.

The accompanying engagement activities, developed in partnership with community organizations and academics, further sought to engage visitors to the museum with climate change in novel and multi-sensory ways, encouraging them to think about climate change in terms of time and place. During exhibition opening hours, researchers and practitioners invited visitors to take part in 'Climate Conversations', talking and telling their own climate change story. Each person took a different approach to their 'climate conversation' using experiments, computer simulations, stories, data and objects as the jumping off points for discussion; the purpose was not to provide information, but instead to present a diverse range of perspectives on the meaning of climate change in the lives of researchers and practitioners and, in so doing, invite visitors to think about what climate change meant to them. Climate Control sought to elicit new visions from the people of Manchester for their city, through the co-creation of alternative futures in the heterotopia of the museum. This took place in different ways including creative mapping and facilitated sessions based on Manchester's Climate Change Strategy, where people built their visions for a sustainable Manchester from Lego, guided by policies on mitigation and adaptation from the city's climate strategy.11 
The triangulation of academia, public engagement and public policy raised challenges of working together, but was aimed at supporting the development of climate change policies within the city, and promoting civic participation among the public. Climate Contro/ drew upon Manchester's industrial heritage and its inextricable link to climate change to create public opportunities directed towards shaping the future (McGhie et al. 2018; McGhie 2019).

\section{Discussion}

As the need for climate action becomes ever more urgent, we argue in this paper that museums have a key role to play, providing a space where people can work through the meaning of climate change in their own lives, and in inspiring and supporting climate actions. More ambitiously, however, we argue that museums can support people's constructive, meaningful and impactful climate change engagement beyond the museum, by developing exhibitions and other events which recognize the psychological distance of climate change. Whilst making climate change closer - more immediate, personal or concrete - is not a silver bullet for enhancing climate change awareness, empowerment and action, working with psychological distance, in terms of time, place and uncertainty in museums, contributes to the perceived distance of climate change from people's everyday lives, which can be a barrier to climate action.

Framing climate engagement through the Big Here and Long Now offers the opportunity to change perceptions of time and place, enabling people to explore and question the relationship between the local and the global or national, and recognize that their 'now' is merely a stopping off point between the past and multiple possible futures which have yet to be created. Through their exhibitions, museums can develop narratives which align with the multiple values of their visitors, telling different stories at the same time. Depending on the narrative, climate change can be made less abstract, or alternatively a narrative could be framed around the abstract aspect of climate change to encourage people to reflect on rights, responsibilities and morality. We suggest that the combination of the Big Here and Long Now with the concept of the heterotopia presents a particularly powerful approach, combining a deep exploration of 'where we are now', from the Big Here and Long Now, with a vision-creating element from the heterotopia: where we are trying to get to. This enriched understanding provides opportunities to explore how we, individually and collectively, will bridge the difference between our current state and the state we desire, regarding climate change.

Museums have a unique role as trusted organizations and spaces where people come not only to be entertained but also to learn; increasingly museums are using their collections in creative ways as sites of social change. Working in collaboration with partners, museums can be part of a coalition of action on climate change, as Manchester Museum sought to do with the Climate Control exhibition and associated activities. For example, the co-creation of future visions for Manchester out of Lego allowed people to explore alternative visions, with such models having a 'performative' purpose, moving discussions away from targets to places, lives and communities. Working with different conceptions of time and place can give people a sense of agency, whereby transformation is something created by people, rather than happening to them (see Cameron and Deslandes 2011). Museums can aim to work with people, as individuals and communities, in co-production and co-creation, to give people agency in their future and its creation: 'Rather than treating audiences as passive species bodies to be reformed, museums need to acknowledge the creative potential of their audiences as valued actors having valued opinions and expertise, skills, capacities, desires, expectations, reflexive capabilities and imagination' (Cameron 2011: 100).

Museums have the potential to provide people with opportunities to explore alternative pasts, presents and futures, and to negotiate the connections (and disconnections) between local and global dimensions, and short and long-term temporalities; in other words, museums can help people (individually and collectively) negotiate the psychological distance dimensions of climate change, and connect them with their own lives. Focussing on local and immediate situations has perhaps the greatest potential to empower people and to consider personal contribution, community and citizenship; while long-term dimensions can provide greater opportunity for creative exploration of more radically different, structural changes to society. 'Starting' with the local may engage people who are not immediately concerned with exploring 
more abstract ideas of the future. The combination of creative, interactive experiences mentioned above, which draw on people's own ideas as much as projecting 'museum narrative' for people to consume, provides a more plausible route for supporting people's ongoing, constructive engagement and dialogue with climate change beyond the museum, going beyond 'mere' intellectual understanding to self-knowledge. Providing opportunities for people to understand, share and respond as part of museum experiences provides opportunities for people to explore and begin to create possible futures together in a safe environment.

If we are to transform society, and our lives, we need spaces that support transformation and that create opportunities to imagine, design and begin to create desirable futures. When we think about the future, we normally do so in the box of our town, our house, our lives. In a museum you are transported to a different place; accepting the museum's function as heterotopia can free you up to imagine new futures with different boundaries and free to explore different times and places (at least in some sense): surely a kind of 'partly enacted utopia' that can be put to work. By providing a space (physical and intellectual) and a frame to consider the present as a point on the journey from the past to one of a myriad of possible futures, museums can begin to reposition themselves to actively promote civic participation and action around climate change.

Received: 5 September 2018

Finally accepted: 11 Mar 2020

\section{Acknowledgments}

An early version of this paper was presented (by $\mathrm{HM}$ ) at the $25^{\text {th }}$ International Congress of the History of Science and Technology (Rio de Janeiro, July 2017) in a symposium on 'Narratives of Future Earth'. HM and SM are grateful to Dr. David Gelsthorpe, Anna Bunney (both Manchester Museum), Dr. Rebecca Cunningham (University of Technology, Sydney) and Jonny Sadler (Manchester Climate Change Agency) for help in developing the Climate Control programme at Manchester Museum.

\section{Notes}

1 https://unfccc.int/resource/docs/convkp/conveng.pdf, https://unfccc.int/sites/default/files/ english_paris_agreement.pdf accessed 24 March 2020.

2 https://sustainabledevelopment.un.org/post2015/transformingourworld accessed 24 March 2020.

3 https://unfccc.int/sites/default/files/resource/cp24 auv L.3 edu.pdfaccessed 16 January 2020.

4 Brian Eno, 'The Big Here and Long Now', http://longnow.org/essays/big-here-and-longnow/ accessed 16 January 2020.

5 https://www.wired.com/1995/12/the-millennium-clock/ accessed 25 March 2020.

6 https://kk.org/helpwanted/archives/001084.php accessed 31 May 2020.

7 See also Peter Johnson, 'Some reflections on the relationship between utopia and heterotopia', Heterotopian Studies, 2012. http://www.heterotopiastudies.com, accessed 25 March 2020.

8 http://www.varldskulturmuseerna.se/en/varldskulturmuseet/ongoing-exhibitions/humannature/about-the-exhibition/ accessed 15 January 2020.

9 https://www.inhumantime.org/ accessed 15 January 2020.

10 https://pweilstudio.com/project/88-cores/ accessed 15 January 2020.

11 Manchester Climate Change Agency (2016), http://www.manchesterclimate.com/sites/ 
default/files/MCCS\%202017-50.pdf, accessed 25 March 2020.

\section{References}

Basu, P. and Modest, W. (2015) Museums, Heritage and International Development, London: Routledge.

Brand, S. (1999) The Clock of the Long Now. Time and Responsibility: The Ideas Behind the World's Slowest Computer, New York: Basic Books.

Broomell, S.B., Budescu, D.V. and Por, H.-H (2015) 'Personal Experience with Climate Change Predicts Intentions to Act', Global Environmental Change, 32 67-73.

Brügger, A., Dessai, S., Devine-Wright, P., Morton, T.A. and Pidgeon, N.F. (2015) 'Psychological Responses to the Proximity of Climate Change', Nature Climate Change, 5 1031-7.

Brügger, A., Morton, T.A. and Dessai, S. (2016) "Proximising' Climate Change Reconsidered: A Construal Level Theory Perspective', Journal of Experimental Psychology, 46 125-42.

Burke, C. and Stott, P. (2017) 'Impact of Anthropogenic Climate Change on the East Asian Summer Monsoon', Journal of Climate, 30 5205-20.

Cameron, F.R. (2007) 'Moral Lessons and Reforming Agendas: History Museums, Science Museums, Contentious Topics and Contemporary Societies', in Simon J. Knell, Suzanne MacLeod and Sheila Watson (eds) Museum Revolutions: How Museums Change and are Changed, 330-42, London: Routledge.

(2010) 'Liquid Governmentalities, Liquid Museums and the Climate Crisis', in Fiona Cameron and Lynda Kelly (eds) Hot Topics, Public Culture, Museums,112-28, Newcastle upon Tyne: Cambridge Scholars.

(2011) 'From Mitigation to Creativity: The Agency of Museums and Science Centres and the Means to Govern Climate Change', Museum and Society, 9 (2) 90-106.

(2012) 'Climate Change, Agencies, and the Museum for a Complex World', Museum Management and Curatorship, 27 (4) 317-39.

Cameron, F.R. and Deslandes, A. (2011) 'Museums and Science Centres as Sites for Deliberative Democracy on Climate Change', Museum and Society, 9 (2) 136-53.

Cameron, F.R., Hodge, B. and Salazar, F. (2013) 'Representing Climate Change in Museum Space and Places', WIREs Climate Change, 4 (1) 9-21.

Cameron, F.R. and Neilson, B. (eds) (2015) Climate Change and Museum Futures, London: Routledge.

Carvalho, A. and Peterson, T.R. (2012) 'Reinventing the Political: How Climate Change Can Breathe New Life into Democracies', in Anabela Carvalho and Tarla Rai Peterson (eds) Climate Change Politics. Communication and Public Engagement, 1-28, New York: Cambria Press.

Chilvers, J., Pallett, H. and Hargreaves, T. (2018) 'Ecologies of Participation in SocioTechnical Change: The Case of Energy System Transitions', Energy Research and Social Science, 42 199-210. 
Committee on Climate Change (2019a) Reducing UK Emissions: 2019 Progress Report to Parliament, London: Committee on Climate Change.

(2019b) Progress in Preparing for Climate Change: 2019 Report to Parliament, London: Committee on Climate Change.

Dorfman, E. (ed) (2018) The Future of Natural History Museums, ICOM Advances in Museums Research, London: Routledge.

Ejelöv, E., Hansla, A., Bergquist, M. and Nilsson, A. (2018) 'Regulating Emotional Responses to Climate Change - A Construal Level Perspective', Frontiers in Psychology, 9 (629) doi.org/10.3389/fpsyg.2018.00629.

Foucault, M. (1986) 'Of Other Spaces', Diacritics, 16 (1) 22-7.

(1998) 'Different Spaces', in James D. Faubion (ed) The Essential Works, vol. 2, Aesthetics, 175-85, London: Allen Lane.

Griffioen, A.M., van Beek, J., Lindhout, S.N. and Handgraaf, M.J.J. (2016) 'Distance Makes the Mind Grow Broader: An Overview of Psychological Distance Studies in the Environmental and Health Domains', Applied Studies in Agribusiness and Commerce, 10 (2-3) 33-46.

Harrison, R. (2013) Heritage: Critical Approaches, Abingdon: Routledge.

Hetherington, K. (1997) The Badlands of Modernity: Heterotopia and Social Ordering, London: Routledge.

(2015) 'Foucault and the Museum', in Andrea Witcomb and Kylie Message (eds) The International Handbooks of Museum Studies: Museum Theory, 21-40, Chichester: John Wiley and Sons.

Hooper-Greenhill, E. (2000) Museums and the Interpretation of Visual Culture, London: Routledge.

Janes, R.R. (2009) Museums in a Troubled World: Renewal, Irrelevance or Collapse?, London: Routledge.

(2016) Museums Without Borders, Abingdon: Routledge.

Janes, R.R. and Sandell, R. (2019) Museum Activism, Abingdon: Routledge.

Jones, C., Hine, D.W. and Marks, D.G. (2017) 'The Future is Now: Reducing Psychological Distance to Increase Public Engagement with Climate Change', Risk Analysis, 37 (2) $331-41$.

Liberman, N. and Trope, Y. (2008) 'The Psychology of Transcending the Here and Now', Science, 322 (5905) 1201-5.

Lord, B. (2006) 'Foucault's Museum: Difference, Representation and Genealogy', Museum and Society, 4 (1) 1-14.

Lorenzoni, I., Nicholson-Cole, S. and Whitmarsh, L. (2007) 'Barriers Perceived to Engaging with Climate Change Among the UK Public and their Policy Implications', Global Environmental Change, 17 (3-4) 445-59.

Marin, L. (1984) Utopics: Spatial Play, London: Macmillan. 
(1992) 'Frontiers of Utopia: Past and Present', Critical Inquiry, 19 (3) 397-420.

McDonald, R.I., Chai, H.Y. and Newell, B.R. (2015) 'Personal Experience and the 'Psychological Distance' of Climate Change: An Integrative Review', Journal of Environmental Psychology, 44 109-18.

McGhie, H.A. (2019) 'Climate Change: A Different Narrative', in Walter Leal Filho, Bettina Lackner and Henry McGhie (eds) Addressing the Challenges in Communicating Climate Change Across Various Audiences, 13-29, Cham (Switzerland): Springer International.

McGhie, H.A., Mander, S. and Underhill, R. (2018) 'Engaging People with Climate Change through Museums', in Walter Leal Filho, Evangelos Manolas, Anabela Marisa Azul, Ulisses M. Azeiteiro and Henry McGhie (eds), A Handbook of Climate Change Communication, vol. 3, 329-48, Cham (Switzerland): Springer.

Moser, S. and Dilling, L. (2004) 'Making Climate Hot: Communicating the Urgency and Challenge of Global Climate Change', Environment, 46 (10) 32-46.

Newell, J., Robbin, L. and Wehner, K. (eds) (2017) Curating the Future: Museums, Communities and Climate Change, Abingdon: Routledge.

O'Neill, S. and Nicholson-Cole, S. (2009) "Fear Won't Do It': Promoting Positive Engagement with Climate Change through Visual and Iconic Representations', Science Communication, 30 355-79.

Pidgeon, N. and Fischhoff, B. (2011) 'The Role of Social and Decision Sciences in Communicating Uncertain Climate Risks', Nature Climate Change, 1 35-41.

Rabinovich, A., Morton, T. and Postmes, T. (2010) 'Time Perspective and AttitudeBehaviour Consistency in Future-Oriented Behaviours', British Journal of Social Psychology, 49 (1) 69-89.

Rabinovich, A., Morton, T.A., Postmes, T. and Verplanken, B. (2009) 'Think Global, Act Local: The Effect of Goal and Mindset Specificity on Willingness to Donate to an Environmental Organization', Journal of Environmental Psychology, 29 (4) 391-9.

Schuldt, J.P., Rickard, L.N. and Yang, Z.J. (2018) ‘Does Reduced Psychological Distance Increase Climate Engagement? On the Limits of Localizing Climate Change', Journal of Environmental Psychology, 55 147-53.

Spence, A., Poortinga, W. and Pidgeon, N. (2012) 'The Psychological Distance of Climate Change', Risk Analysis, 32 (6) 957-72.

Trope, Y. and Liberman, N. (2010) 'Construal-Level Theory of Psychological Distance', Psychological Review, 117 (2) 440-63.

UNESCO (2015) Global Citizenship Education: Topics and Learning Objectives, Paris: UNESCO.

(2017) Education for Sustainable Development Goals: Learning Objectives, Paris: UNESCO.

Van Boven, L., Kane, J., McGraw, P.A. and Dale, J. (2010) 'Feeling Close: Emotional Intensity Reduces Perceived Psychological Distance', Journal of Personality and Social Psychology, 98 (6) 872-85.

Van Oldenborgh, G.J., Van der Wiel, K., Sebastian, A., Singh, R., Arrighi, J., Otto, F., 
Haustein, K., Li, S.H., Vecchi, G. and Cullen, H. (2017) 'Attribution of Extreme Rainfall from Hurricane Harvey, August 2017', Environmental Research Letters, 12.

Wang, S., Hurlstone, M., Leviston, Z., Walker, I., and Lawrence, C. (2019) 'Climate Change from a Distance: An Analysis of Construal Level and Psychological Distance from Climate Change', Frontiers in Psychology, 10 (230), doi.org/10.3389/ fpsyg.2019.00230.

Whitmarsh, L., O'Neill, S. and Lorenzoni, I. (2011) Engaging the Public with Climate Change: Behaviour Change and Communication, London: Earthscan.

\section{Authors \\ *Henry McGhie, Curating Tomorrow, 40 Acuba Road, Liverpool UK, L15 7LR, henrymcghie@curatingtomorrow.co.uk \\ Tel: 07402659372}

Henry McGhie has a background as an ornithologist, museum curator and senior manager. He has been working on sustainability, climate change and museums for over 15 years, developing exhibitions, working with local and international policy workers, organizing international conferences and editing two books on the subject. He established Curating Tomorrow in 2019 as a consultancy for museums and the heritage sector, helping them draw on their unique resources to enhance their contributions to society and the natural environment, the Sustainable Development Goals, climate action and nature conservation. He is a member of the International Council of Museums Working Group on Sustainability.

**Sarah Mander, Tyndall Centre for Climate Change Research, University of Manchester, M13 9QL, s.mander@manchester.ac.uk

Tel: 01613063259

Dr Sarah Mander is a Reader in Energy and Climate Policy and an interdisciplinary energy researcher, with over a decade's experience using deliberative and participatory approaches to understand social, institutional and governance barriers to climate mitigation. For the past five years, she has coordinated Tyndall Manchester's public engagement activities, working with museums, schools and community organizations to develop arts-based and creative approaches to climate change engagement, including theatre games and performance art. Dr Mander is a member of the Centre for Climate Change and Social Transformations (CAST), where her work combines her expertise in social responses to low-carbon technology with her belief that, in the absence of effective action on climate change from governments, innovation by grass-roots organizations is key to driving the low-carbon transition.

${ }^{* * *}$ Asher Minns, Tyndall Centre for Climate Change Research, University of East Anglia, Norwich, a.minns@uea.ac.uk

Asher Minns is a science communicator specialising in knowledge transfer of climate change and other global change research to audiences outside of academia. He has over two decades in practice, and is also the Executive Director of the Tyndall Centre for Climate Change Research. 